\title{
Capillary Tube Device
}

National Cancer Institute

\section{Source}

National Cancer Institute. Capillary Tube Device. NCI Thesaurus. Code C50237.

A tube with a narrow diameter designed to hold a liquid by capillary action. 